\title{
‘Prostate Cancer' Information on the Internet: Fact or Fiction?
}

\begin{abstract}
Yusuf Moolla $^{\mathrm{a}^{*}} \quad$ Ahmed Adam $^{\mathrm{b}^{*}} \quad$ Marlon Perera $^{\mathrm{c}} \quad$ Nathan Lawrentschuk $^{\mathrm{d}}$
aDepartment of Oncology, Klerksdorp Hospital, Klerksdorp/Tshepong Hospital Complex, Klerksdorp, North West Province; ${ }^{\text {DDepartment }}$ of Urology, Helen Joseph Hospital \& Department of Paediatric Urology, Rahima Moosa Mother \& Child (Coronation) Hospital, Division of Urology, Department of Surgery, Faculty of Health Sciences, School of Clinical Medicine, University of the Witwatersrand, Johannesburg, South Africa; 'Department of Surgery, Austin Health, University of Melbourne, VIC and Department of Surgery, University of Queensland, Brisbane, QLD; ${ }^{d}$ Department of Surgery, Austin Health, University of Melbourne, and Olivia-Newton John Cancer Centre, University of Melbourne, and Department of Surgical Oncology, Peter MacCallum Cancer Centre, Melbourne, VIC, Australia
\end{abstract}

*Y. Moolla and A, Adam shared co-first authorship.

\section{Key Words}

Prostate cancer • DISCERN score • Health on the Net seal • Internet information quality • JAMA Benchmarks

\begin{abstract}
Background/Aims: In today's information era, patients often seek information regarding health using the internet. We assessed reliability and validity of internet information regarding 'prostate cancer'. Methods: Search term 'prostate cancer' used on Google website (June 2017). Critical analysis was performed on first 100 hits using JAMA benchmarks, DISCERN score, Health on the Net. Results: 33500000 hits returned. Top 100 hits were critically analyzed. Ten links [duplicate links $(n=7)$, book reviews $(n=1)$, dead sites $(n=2)]$ were excluded, therefore 90 were analyzed. Subcategories assessed included: commercial (53.33\%), university/medical center (24.44\%), government (13.33\%); non-governmental/ non-profit organizations (8.89\%). Sub-type of information content assessed included: factual (74.44\%), clinical trials (18.89\%); stories (5.56\%); question and answer (1.11\%). Website rated as HONcode seal positive $(14,44 \%)$ or seal negative $(85,56 \%)$. Website content based on JAMA benchmarks: 0 benchmarks (4.44\%), 1 benchmark (16.67\%), 2 benchmarks (34.44\%),3 benchmarks(27.78\%),4benchmarks(16.67\%).DISCERN score rated: 'low' score (16-32) = 12 websites $(13.33 \%)$, 'moderate' score (33-64 points) $=68$ websites $(75.56 \%)$,
\end{abstract}

\section{KARGER}

Fax +4161306 1234

E-Mail karger@karger.com

www.karger.com
(C) 2020 The Author(s)

Upen access

This article is licensed under the Creative Commons AttributionNonCommercial-NoDerivatives 4.0 International License (CC BYNC-ND) (http://www.karger.com/Services/OpenAccessLicense) Usage and distribution for conme 'high' score ( $\geq 65$ points $)=10$ websites $(11.11 \%)$. Conclusion: Critical assessment of 'Prostate Cancer' information on the internet, showed that overall quality was observed to be accurate, however majority of individual websites are unreliable as a source of information by itself for patients. Doctors and patients need to be aware of this 'quality vs quantity' discrepancy when sourcing PCa information on the internet.

(c) 2020 The Author(s)

Published by S. Karger AG, Basel

\section{Introduction}

Prostate cancer (PCa) is the second most common cancer in men worldwide [1]. In 2012, an estimated 14.1 million new cases of cancer were diagnosed worldwide, of which just over 1.1 million were PCa cases, accounting for about $8 \%$ of all new cancer cases and about $15 \%$ of cancers in men [2]. This makes PCa the 4th most prevalent cancer in both sexes combined, with almost $70 \%$ of all cases being diagnosed in more developed regions of the world [3].

Greater access to medical information provides patients with a valuable tool for self-education [4], and an opportunity for better-informed decision making and greater participation in overall care [5]. However, the reliability, validity, completeness and relevance of the 
information may be questionable, since sources of information on the internet are varied and are largely unregulated. The result is that the quality of information that reaches the patient is inconsistent [6]. This is further supported by several studies of single medical conditions, which suggested deficiencies in the quality of Web-based health information [7].

Thus, we aimed to objectively assess the quality and validity of 'prostate cancer' information currently available on the internet, more specifically on the Google platform.

\section{Materials and Methods}

\section{Search Strategy}

The search term 'prostate cancer' was used (11th June 2017) on the Google search engine (www.google.com). The search was done using an updated browser of Internet Explorer Version 11 (most recent version with all available updates installed). The website itself was to be evaluated as part of the critical assessment and not just the landing page of the Google search results. Therefore, if further information was obtained elsewhere on the website via subheadings, links, or leading pages, this information retrieved was considered to be obtained as a result of being directed to it, either directly or indirectly, via the 'original' Google search. The study search was limited to the English language only.

\section{Categorization}

The websites reviewed were categorized based on: affiliation (commercial, university/medical center, non-profit organization, government), content type (medical facts, clinical trials, human interest stories, question and answer), and specialization of topic and content (website exclusively related to $\mathrm{PCa}$ or only part of website).

\section{Quality Assessment Instruments}

Several quality evaluation tools have been developed in order to assess health information using various criteria. Amongst the many tools available, we selected 3 different, validated evaluation tools for this specific study. These included the Health on the Net Foundation (HON) code [8, 9], the Journal of American Medical Association (JAMA) benchmarks [10] and the DISCERN tool [11].

\section{HON code}

HON is a non-profit organization based in Switzerland and founded in 1995. It is one of the first Uniform Resource Locator used as a guide to reliable sources of healthcare information on the internet. It proposes a voluntary 8-point code of conduct comprising 8 ethical principles: (authoritative; complementarity; privacy; attribution; justifiability; transparency; financial disclosure; advertising policy). Any website which complies with this code is granted permission to display the HON award-like badge on its website upon request. The certificate is valid for 1 year after which the website needs to be re-evaluated before obtaining re-certification. The HON code is the oldest quality evaluation tool being used to date $[8,9]$.

'Prostate Cancer' and the Internet: Fact or Fiction?
Using a 2-step verification process, the websites were then assessed for the HON Code of Conduct (HONcode) quality certification $[8,9]$. Firstly, each site was manually checked for the HON seal to determine certification status. If the website displayed the HONcode badge (seal), its current validity was further counterchecked by clicking on the active and dynamic badge. This leads to a page on the HON servers, containing the website's actual certificate which displays the initial certification date as well as the current validity status. Both these parameters were recorded for study purposes.

\section{JAMA Benchmarks}

The JAMA benchmarks are another widely used quality evaluation tool. In a JAMA article in 1997, Silberg et al. [10] proposed a set of criteria designed to assess and evaluate the quality of health information on the internet. These benchmarks are namely: authorship of medical content, attribution of source of information, disclosure of ownership of webpage and any conflict of interest and currency of posted content.

Each website was evaluated to determine if they met the JAMA benchmark criteria [10]. The 4 criteria covered in this validation process are: authorship, attribution, currency, and disclosure. Authorship requires that authors and contributors names, affiliations and credentials are displayed on the website. Attribution refers to effective referencing of all content of the website. Currency requires that the website include dates of when the content was first posted and when was the last update. Disclosure demands that the website's ownership and any potential conflict of interest are stated as well as any sponsorship or advertising. These scores were assessed by the authors and recorded accordingly.

\section{DISCERN Criteria}

DISCERN is a valid and reliable 16-point questionnaire to aid health consumers and information providers in evaluating the quality of health information on any website they wish to evaluate. It was launched in 1998 and created by the Division of Public Health and Primary Care at Oxford University, London [11]. It is comprised of 3 distinct set of questions: Section 1 (questions $1-8$ ) assesses reliability; section 2 (questions 9-15) focuses on the quality of information about treatment choices; section 3 (question 16) provides an overall quality rating of the publication independent of the previous 15 questions. Each question is then scored on a range from 1 (definite NO) to 5 (definite YES). A score of $2-4$ is a range given in cases which the criterion is partially met to some extent. The maximum total score for all 16 questions is 80 , and the quality of each website is classified as high ( $\geq 65$ points), moderate (33-64 points), or low (16-32 points). As with the validation tools above, scoring and grading was performed on all sites retrieved.

\section{Results}

The Google search returned 33,500,000 hits, the first 100 of which were critically analyzed (table 1 ). Ten websites were excluded due to being duplicate links ( 7 websites), dead links ( 2 websites) or book previews (1 web-

Curr Urol 2019;13:200-208 


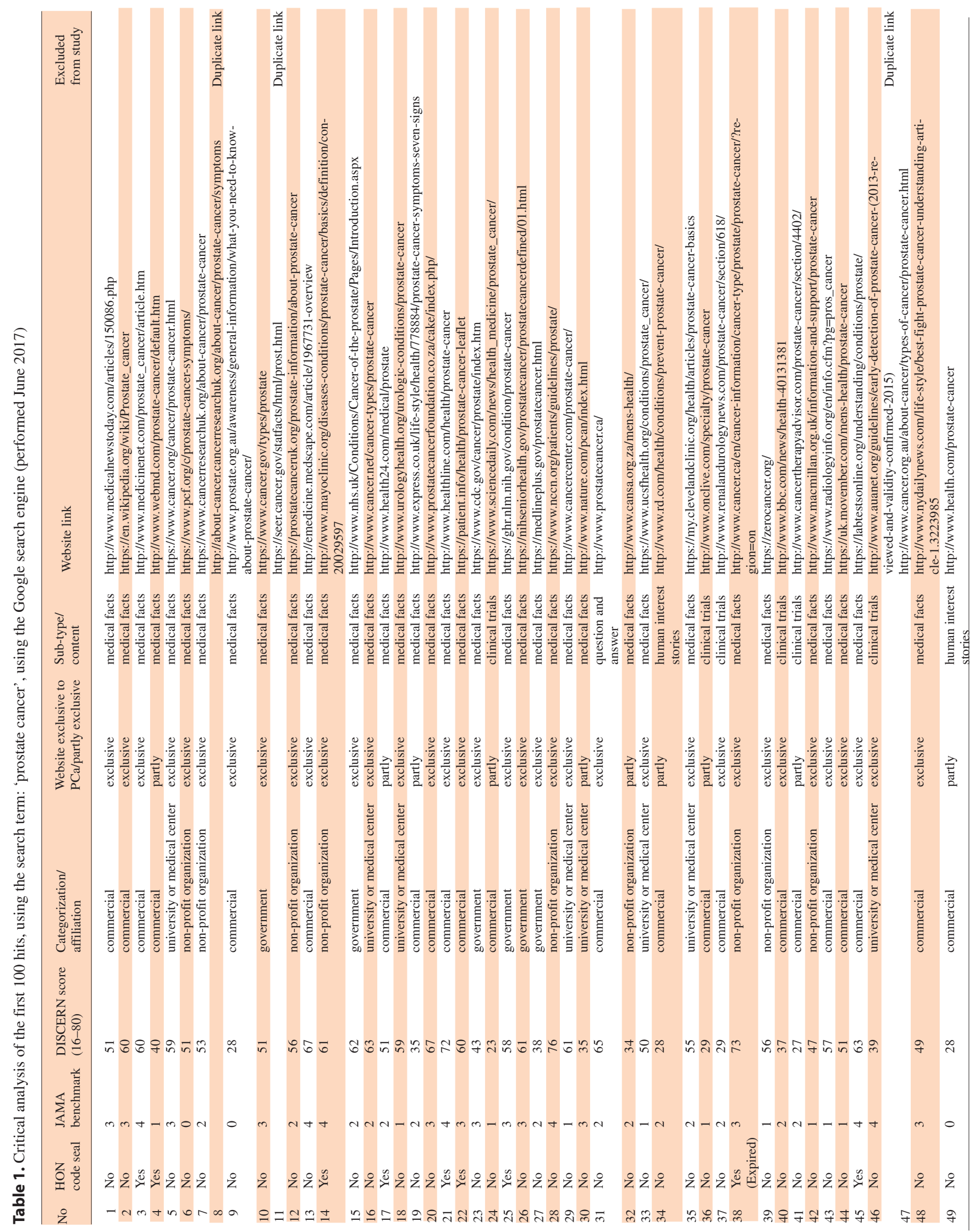




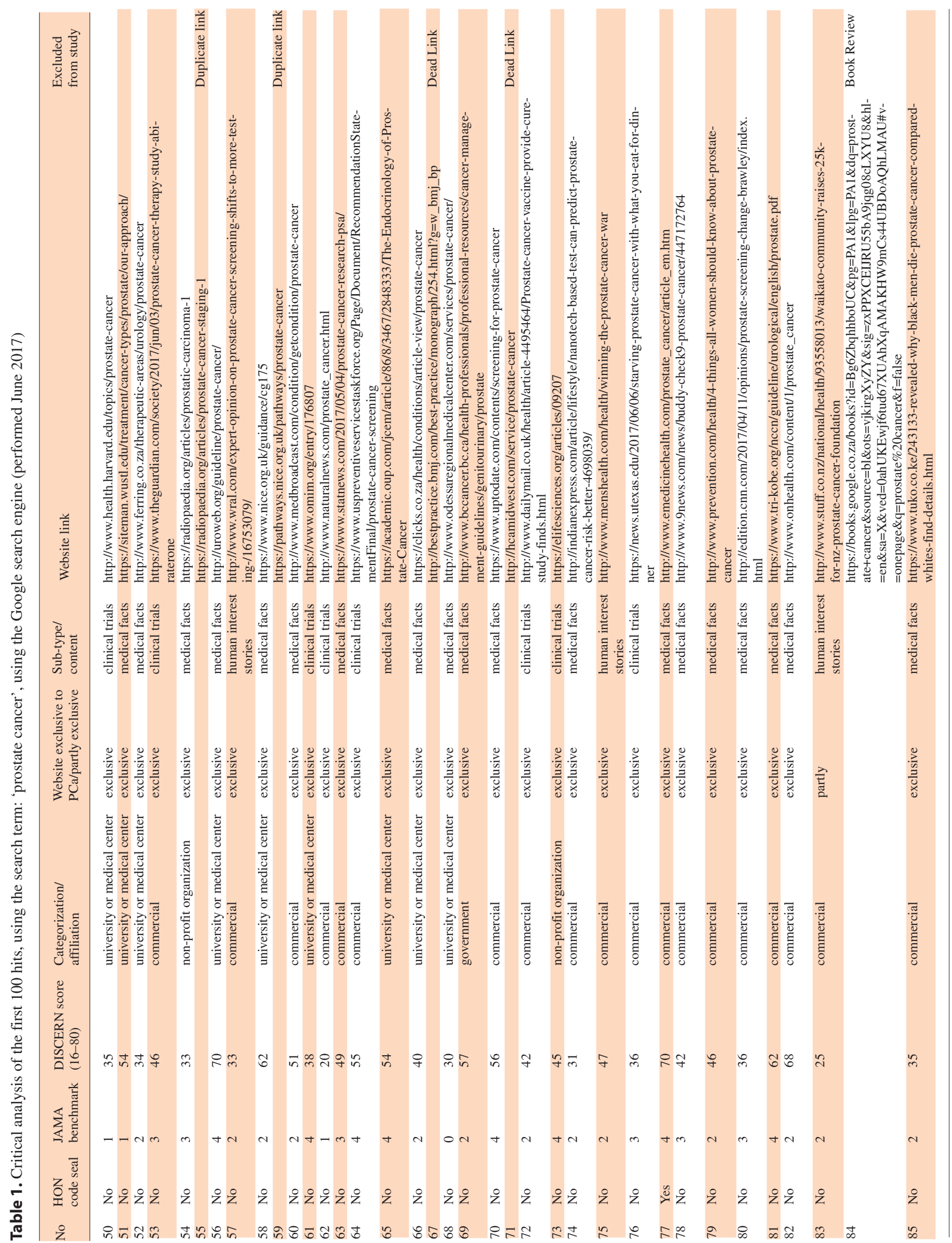




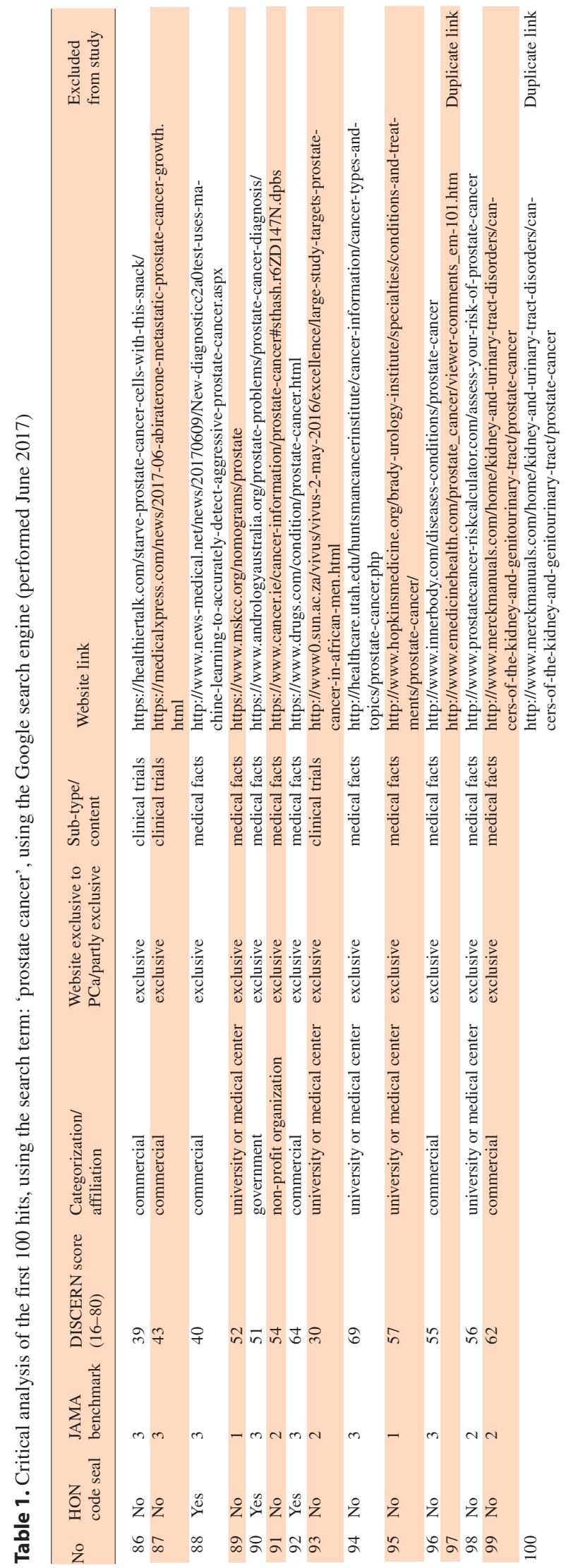

site), leaving a total of 90 websites for further evaluation and critical appraisal. Majority (79/90) of the websites were exclusive to $\mathrm{PCa}$ in terms of content displayed.

When assessing for the categories returned, more than half $(\mathrm{n}=48,53.33 \%)$ were commercial websites. A further 22 websites were affiliated to universities or medical centers and accounted for almost another quarter $(24.44 \%)$. Eight government websites made up $8.89 \%$ of the websites, with the remaining $13.33 \%$ of websites being affiliated to non-profit organizations $(n=12)$. By far, the majority of websites $(n=67)$ contained medical information of a factual nature $(74.4 \%)$, with clinical trials $(\mathrm{n}=17)$ accounting for $18.89 \%$.

In terms of quality and validity of information, the HONcode seal was displayed on only $14.44 \%$ of websites $(n=14)$, while the remaining $85.56 \%$ of websites $(n=76)$ did not have any evidence of certification by the HON (fig. 1). JAMA benchmarks were only fully met by $16.67 \%$ of websites $(n=15)$. A further 25 websites $(27.78 \%)$ achieved 3 out of 4 benchmarks. Most websites $(\mathrm{n}=31,34.4 \%)$ met 2/4 JAMA benchmarks and 15 $(16.67 \%)$ of websites only achieved 1 JAMA benchmark and 4 (4.44\%) did not achieve any benchmarks (fig. 2).

Application and scoring utilizing the DISCERN criteria revealed $10 / 90$ websites $(11.11 \%)$ that achieved a 'high' score ( $\geq 65$ points), with the highest score by any website being 76 (out of a potential maximum of 80). A moderate score (33-64 points) was obtained by $75.56 \%$ of websites $(\mathrm{n}=68)$, and the remaining 12 websites (13.33\%) achieved a low score (16-32) (fig. 3).

The four overall best performing websites (Table 1 . Link numbers $21,77,28,38$ ), either meeting criteria or coming close to having concurrent HON Positive; JAMA 4/4 \&; DISCERN $\geq 65$ points included two websites particularly (Link numbers $21 \& 77$ ), with HONcode seal positive, JAMA benchmarks $4 / 4$ and more specifically have very high DISCERN scores ( $\geq 70$ out of 80 )."

Amongst the websites with the poorest validation scores (table 1. Link numbers 9, 49, 68, 24, 62), 3 links have no JAMA benchmarks, no HONcode seal, and relatively low DISCERN score (16-32), while 2 other links have only 1 JAMA benchmark, no HONcode seal and a very low DISCERN score.

\section{Discussion}

Health information is one of the most sought after topics on the internet [12]. Access to internet worldwide has rapidly evolved since the advent of this information plat- 


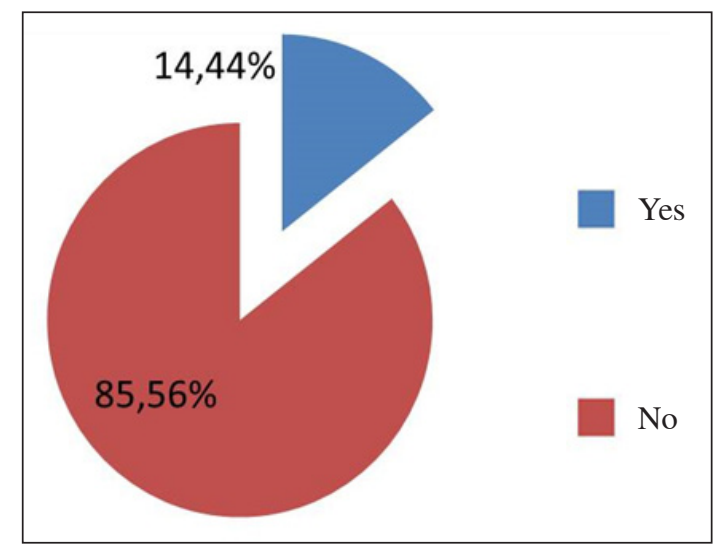

Fig. 1. HONcode seal.

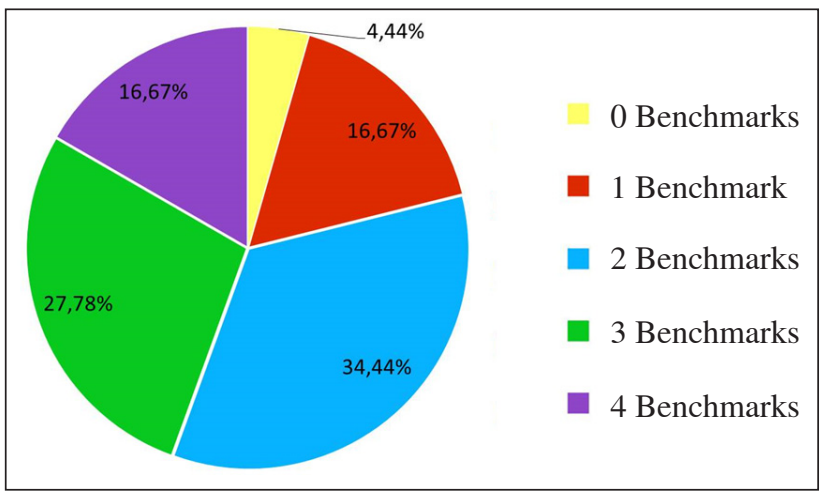

Fig. 2. JAMA Benchmarks.

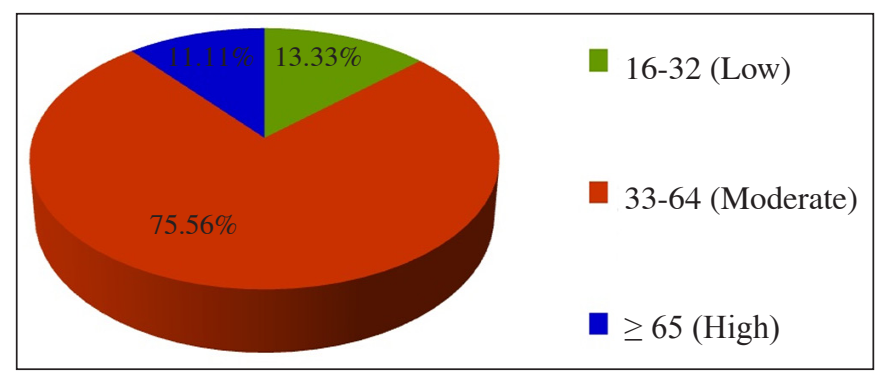

Fig. 3. JAMA Benchmarks.

form. According to the International Telecommunication Union Facts and Figures 2016 report, just under 3.5 billion (3.48 billion) individuals were estimated to be using

'Prostate Cancer' and the Internet: Fact or Fiction? the internet worldwide. This figure has increased from 1.15 billion or $17.6 \%$ from the previous decade [13]. The Internet world stats online website quotes an impressive 3.79 billion internet users as at 31 March 2017, which at $49.7 \%$ just falls short of half of the global population. This represents a growth of $936 \%$ since the turn of the millennia in 2000 [14]. As a result of the rapid expansion of the internet, both in terms of users and to the volumes of information available online, it has become the single largest source of information worldwide [6]. Health information has also seen an exponential increase in accessibility online and has become an increasingly important source of health-related information for patients [7].

A recent study found that $75 \%$ of people who go online seek health information and also that $75 \%$ in a health crisis use the internet to aid in decision-making [15]. Steinberg et al. [16] reported that approximately $56 \%$ of PCa patients seek health information online. While, Valero-Aguilera et al. [17] found that only $11.2 \%$ of patients in the study population reported using the internet as a source of health information. This variation may be explained by discrepancies in terms of age, demographics, and other socio-economic factors. These variations in the findings of the select studies mentioned above, amongst many others [18-21], support the view that generalization cannot be made with regard to internet use for health information, as this is highly dependent on the particular study population assessed.

Evaluation of YouTube videos found that YouTube is an inadequate source of $\mathrm{PCa}$ information for patients, in terms of information content and the presence of bias [16]. In another study that focused on determining what patients seek from an internet site, it was determined that the information given was unsatisfactory, from a patient's perspective [22]. Patients would at times, be unable to acquire the critical information easily without being aided by their physician to the appropriate resources. The degree of coverage is highly variable and there is a deficiency in balance of evidence found on many sites [23].

However, a more recent study found an acceptable and 'encouraging' degree of quality and reliability of PCa information on the web using various quality tools (DISCERN; HONcode; JAMA benchmarks; the LIDA instrument; Automated Readability Index; and the Flesch-Kincaid readability tests). Although the limitations of this study was the isolated assessment of a select few popular websites which were amongst the 'top 10' hits on 3 of the most popular search engines [24].

Besides the internet, another related information source utilized by patients involve the use of Mobile Ap- 


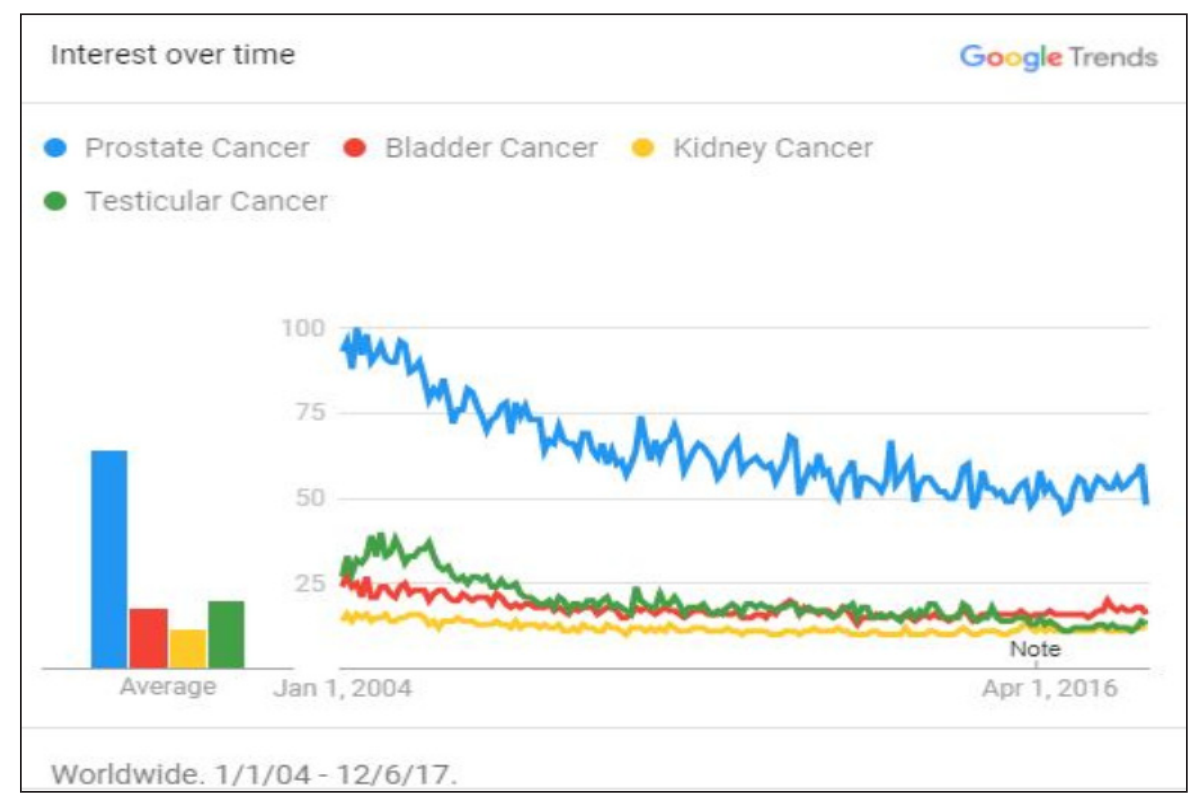

Fig. 4. A screen shot (Google trend) of the trend over time (January 2004 to December 2017) of searches performed for urological malignancies on the Google platform (Y-axis units: Numbers represent search interest relative to the highest point on the chart for the given region and time. A value of 100 is the peak popularity for the term, and a value of 50 means that the term is half as popular).

plications (Apps). This platform, like the internet in general, also requires more stringent validation and review to ascertain the reliability and quality of information sent out to patients with $\mathrm{PCa}$ [25].

When assessing for the patterns of search amongst all urological malignancies, $\mathrm{PCa}$ has been the commonest search term utilized (fig. 4) depicted by the Google Trends data [26], which shows that PCa searches were the most common since 2004 to present. In comparison to the other genitourinary cancers, $\mathrm{PCa}$ is searched for approximately 3 times more than bladder cancer, which is currently the second most popular amongst the urological tumors. Interest in testicular cancer (which from 2004 until 2006 was by far the second-most searched for on Google amongst the urological malignancies), has steadily declined over time and is now searched for at almost the same frequency as kidney cancer, which has almost always being the 4th most popular amongst the 4 cancers represented.

After assessing the websites using the pre-defined tools (table 1), we have found that the information available on the internet is not entirely reliable and complete in itself as an independent source for health information on PCa. Overall 3 websites performed very poorly, demonstrating no JAMA benchmarks, no HONcode seal, and relatively 'low' DISCERN score. On the other hand, 2 websites were HONcode seal positive, JAMA benchmarks $4 / 4$ and had 'high' DISCERN scores $(\geq 65)$. Although most information presented is fairly accurate, it often lacks critical detail on key aspects, which could have negative impact on patient decisions regarding their condition, outcome and their treatment choices. However, the information may serve as a guide to empower patients to gain a better understanding into the condition.

In this internet-driven era, it is imperative that internet users validate information obtained with reliable sources. It also adds an extra dimension to the medical consultation in requiring doctors to assist patients in validating information obtained via the internet and guiding them towards the most reliable, reputable resources on the online domain.

Most of the studies evaluated in the literature had found that patients who utilize the internet as a source of health information, find it to be an effective tool to 
supplement knowledge but not as a primary source of information [27-29]. One of the benefits of using multiple sources of health information is that patients are better able to equip themselves with the understanding of the nature of their illness and the various treatment modalities which may be available. By bringing this information to the consultation, it transforms the doctor-patient relationship and promotes patients to play a more active role in shared-decision making.

The study was limited to the English language only. Secondly, the internet and search engines are dynamic processes that constantly change. Therefore, the websites assessed in this investigation may not necessarily reflect the information available to patients at another point in time. Another limitation of this review would be the exclusion of all other search engines utilized in today's era, however for the purpose of this study, only 'Google' was utilized, since it is by far the commonest search engine used, with well over 3 billion searches daily [30].

\section{Conclusion}

In the evaluation and critical assessment of PCa information on the internet, using three different quality evaluation tools, the overall quality was observed to be accurate, however majority of individual websites are generally unreliable in itself as a source of information for patients. Healthcare professionals and their patients need to be acquainted with this 'quality vs. quantity' discrepancy when sourcing PCa information on the internet. This discrepancy is becoming a more important variable in the everyday counselling of the modern day patient with PCa.

\section{Acknowledgement}

The authors are grateful to Mrs Anna Welman, Department of Surgery, Helen Joseph Hospital, University of Witwatersrand, Johannesburg, for her secretarial support in the drafting of this manuscript.

\section{References}

1 World Cancer Research Fund International: Prostate cancer statistics. http://www.wcrf. org/int/cancer-facts-figures/data-specificcancers/prostate-cancer-statistics. Accessed 20 July 2017

2 World Cancer Research Fund International: Worldwide Data. http://www.wcrf.org/int/ cancer-facts-figures/worldwide-data.Accessed 20 July 2017.

- 3 Ferlay J, Soerjomataram I, Dikshit R, Eser S, Mathers C, Rebelo M, Parkin DM, Forman D, Bray F: Cancer incidence and mortality worldwide: sources, methods and major patterns in GLOBOCAN 2012. Int J Cancer 2015;136:E359-386.

4 Ziebland S, Chapple A, Dumelow C, Evans J, Prinjha S, Rozmovits L: How the internet affects patients' experience of cancer: a qualitative study. BMJ 2004;328:564.

5 Goldsmith J: How will the Internet change our health system? Health Aff (Millwood) 2000;19:148-156.

6 Fahy E, Hardikar R, Fox A, Mackay S: Quality of patient health information on the Internet: reviewing a complex and evolving landscape. Australas Med J 2014;7:24-28.

'Prostate Cancer' and the Internet: Fact or Fiction?
7 Berland GK, Elliott MN, Morales LS, Algazy JI, Kravitz RL, Broder MS, Kanouse DE, Muñoz JA, Puyol JA, Lara M, Watkins KE, Yang H, McGlynn EA: Health information on the Internet: accessibility, quality, and readability in English and Spanish. JAMA 2001;285:2612-2621.

8 Health on the Net (HON): Health on the Net Code of Conduct (HONcode). http://www. hon.ch/HONcode/. Accessed 20 July 2017.

9 Health on the Net. https://www.healthonnet. org/. Accessed 20 July 2017.

10 Silberg WM, Lundberg GD, Musacchio RA: Assessing, controlling, and assuring the quality of medical information on the Internet: Caveant lector et viewor - Let the reader and viewer beware. JAMA 1997;277:1244-1245.

11 Charnock D, Shepperd S, Needham G, Gann R: DISCERN: an instrument for judging the quality of written consumer health information on treatment choices. J Epidemiol Commun Health 1999:53:105-111.

12 McMullan M: Patients using the internet to obtain health information: how this affects the patient-health professional relationship. Patient Educ Couns 2006;63:24-28.
13 International Telecommunication Union: ICT Facts and Figures 2017. http://www.itu.int/ en/ITU-D/Statistics/Pages/facts/default.aspx. Accessed 20 July 2017.

14 Miniwatts Marketing Group: Internet World Stats - usage and population statistics. http:// www.internetworldstats.com/stats.htm. Accessed 20 July 2017.

-15 Dickerson SS, Reinhart A, Boemhke M, Akhu-Zaheya L: Cancer as a problem to be solved: internet use and provider communication by men with cancer. Comput Inform Nurs 2011;29:388-395.

16 Steinberg PL, Wason S, Stern JM, Deters L, Kowal B, Seigne J: YouTube as source of prostate cancer information. Urology 2010; 75:619-622.

17 Valero-Aguilera B, Bermúdez-Tamayo C, García-Gutiérrez JF, Jiménez-Pernett J, Vázquez-Alonso F, Suárez-Charneco A, Guerrero-Tejada R, Cózar-Olmo JM: Factors related to use of the Internet as a source of health information by urological cancer patients. Support Care Cancer 2012;20:3087-3094. 
18 Wallington SF: The Internet as an emerging patient education tool among African American men with prostate cancer: an exploratory study. Am J Mens Health 2008;2:106-121.

19 van de Poll-Franse LV, van Eenbergen MC: Internet use by cancer survivors: current use and future wishes. Support Care Cancer 2008;16:1189-1195.

20 Buntrock S, Hopfgarten T, Adolfsson J, Onelöv E, Steineck G: The Internet and prostate cancer patients searching for and finding information. Scand J Urol Nephrol 2007; 41:367-374.

-21 Pautler SE, Tan JK, Dugas GR, Pus N, Ferri M, Hardie WR, Chin JL: Use of the internet for self-education by patients with prostate cancer. Urology 2001;57:230-233.

$>22$ Rozmovits L, Ziebland S: What do patients with prostate or breast cancer want from an Internet site? A qualitative study of information needs. Patient Educ Couns 2004;53:57-64.
23 Black PC, Penson DF: Prostate cancer on the Internet - information or misinformation? J Urol 2006;175:1836-1842.

24 Borgmann H, Wölm JH, Vallo S, Mager R, Huber J, Breyer J, Salem J, Loeb S, Haferkamp A, Tsaur I: Prostate cancer on the Web - expedient tool for patients' decisionmaking? J Cancer Educ 2017;32:135-140.

25 Adam A, Hellig JC, Perera M, Bolton D, Lawrentschuk N: 'Prostate Cancer Risk Calculator' mobile applications (Apps): a systematic review and scoring using the validated user version of the Mobile Application Rating Scale (uMARS). World J Urol 2018; 36:565-573.

26 Google Trends: https://trends.google.com/ trends/explore date $=$ all $\& \mathrm{q}=$ Prostate $\% 20$ Cancer,Bladder\%20Cancer,Kidney\%20Cancer,Testicular\%20Cancer. Accessed 20 December 2017.
27 Schrijvers J, Vanderhaegen J, Van Poppel H, Haustermans K, Van Audenhove C: How do patients between the age of 65 and 75 use a web-based decision aid for treatment choice in localized prostate cancer? J Evid Based Med 2013;6:167-172.

28 Gilbert SM, Sanda MG, Dunn RL, Greenfield TK, Hembroff L, Klein E, Saigal CS, Pisters L, Michalski J, Sandler HM, Litwin MS, Wei JT: Satisfaction with information used to choose prostate cancer treatment. J Urol 2014;191:1265-1271.

29 Salonen A, Ryhänen AM, Leino-Kilpi H: Educational benefits of Internet and computer-based programmes for prostate cancer patients: a systematic review. Patient Educ Couns 2014;94:10-19.

30 Internet Live Stats: Google Search Statistics. http://www.internetlivestats.com/googlesearch-statistics/. Accessed 01 August 2018. 